\title{
O livro didático de língua portuguesa: novas possibilidades de abordagem no ensino da sintaxe
}

\author{
Adriana Aparecida da Silva \\ Universidade Estadual Paulista "Júlio de Mesquita Filho" (UNESP), \\ Araraquara, São Paulo, Brasil \\ adri.ours@bol.com.br
}

DOI: http://dx.doi.org/10.21165/el.v46i2.1550

\begin{abstract}
Resumo
O livro didático é um dos instrumentos mais presentes nas salas de aula das escolas públicas. De modo geral, trata-se de um dos poucos recursos dos quais o professor dispõe para sua atuação. Neste trabalho, pretende-se mostrar que os livros didáticos de língua portuguesa, com o passar do tempo, apresentam significativa melhora em relação à abordagem de conteúdos gramaticais. A partir de uma análise comparativa entre livros didáticos mais antigos (anteriores aos Parâmetros Curriculares Nacionais) e atuais, é possível observar uma importante evolução na abordagem destinada aos estudos da sintaxe. Pretende-se ainda, à luz da concepção funcionalista, apresentar subsídios para o ensino da língua portuguesa a partir das atividades já presentes no material didático.
\end{abstract}

Palavras-chave: livro didático; sintaxe; ensino.

The Portuguese textbook: new possibilities of approach to teaching syntax

\begin{abstract}
The textbook is one of more frequent instruments in the classrooms of public schools. Generally, it is one of the few resources that the teacher has for his performance. In this work, we intend to show that the textbooks in Portuguese language, in the course of time, show a significant improvement in relation to the grammatical contents approach. From a comparative analysis between older textbooks (previous to PCNs [Parâmetros Curriculares Nacionais - Brazilian Curriculum Parameters]) and other more current ones (after PCNs), we can see a major change in the approach to syntax studies. In addition, the aim is, in the light of functionalist design, to contribute for Portuguese language teaching from activities already present in the schoolbook.
\end{abstract}

Keywords: textbooks; syntax; teaching.

\section{Introdução}

Nosso ponto de partida é a constatação de que existe uma problemática envolvendo o ensino de gramática na sala de aula. Os professores sentem-se inseguros em relação ao que ensinar e como fazer bom uso do material didático disponível: o livro didático. Neste artigo, procuramos discutir possibilidades para um trabalho mais significativo do ensino e aprendizagem da sintaxe a partir da exploração de conteúdos veiculados em livros didáticos publicados antes e depois dos Parâmetros Curriculares Nacionais (BRASIL, 1997). Partimos do pressuposto de que, com o passar do tempo, os livros didáticos apresentaram uma significativa evolução em relação à abordagem de conteúdos gramaticais, especificamente da sintaxe. Entretanto, sabemos que ainda 
perdura no ambiente escolar um ensino de gramática calcado nos princípios da gramática normativa. Procuramos, com este trabalho, apresentar uma contribuição para alterar essa realidade.

A partir de experiências vividas em sala de aula, é possível dizer que o ensino das regras ditadas pela gramática tradicional não apresenta resultados satisfatórios em relação ao trabalho com a língua portuguesa. Entretanto, quando consideramos o uso efetivo da língua, em seus diversos níveis - especialmente os níveis sintático, semântico e pragmático - podemos despertar, através de atividades epilinguísticas, um envolvimento maior do aluno em relação ao seu aprendizado, possibilitando um desenvolvimento mais eficiente de suas habilidades linguísticas.

Considerando que o material didático mais presente nas salas de aula das escolas públicas é o livro didático (LD), optamos por constituir nosso corpus com LD anteriores e posteriores aos Parâmetros Curriculares nacionais, com o objetivo de analisar a melhora que diferentes LD apresentam ao longo de diferentes épocas e sugerir como o professor pode aproveitar esse material em suas aulas. Buscando apresentar uma discussão mais aprofundada sobre a sintaxe, em nossa análise, priorizamos o estudo das orações principais de orações subordinadas substantivas (ou completivas). Nas análises destinadas a esse conteúdo gramatical, tradicionalmente, focalizam-se apenas as orações subordinadas quanto à função sintática que exercem em relação à oração principal. Entretanto, de acordo com a perspectiva funcionalista, norteadora deste trabalho, a análise das orações principais é fundamental para a compreensão dos processos de combinação de orações, uma vez que apresentam em sua composição aspectos formais, semânticos e discursivo-pragmáticos associados à intenção do falante.

\section{A problemática presente no ensino de gramática}

A concepção de gramática, especialmente no tocante à estrutura da língua e a sua normatividade, como uma força controladora que preserva a língua contra possíveis ameaças de desaparecimento ou até mesmo de declínio, é uma concepção que herdamos dos gregos (ANTUNES, 2009, p. 36). Como consequência, foi sendo destinada à gramática a função de controlar o uso da língua, conduzir o comportamento verbal dos usuários, por meio da imposição de modelos ou de padrões. Tal definição de gramática denominada normativa - se consolidou a ponto de reprimir outras concepções menos diretivas. Dessa forma, inúmeros equívocos se formaram acerca do que deve constituir o ensino de gramática.

A prática de um ensino de regras que se mostram isoladas de um contexto ou da funcionalidade comunicativa não pode representar o que seja gramática; devemos buscar uma associação entre seu ensino e a realidade dos alunos. Assim, seu ensino tem como um dos objetivos levar o aluno a refletir sobre a própria língua, fazendo com que ele perceba que tem instrumentos para melhorar o desempenho linguístico. Tendo como meta valorizar as várias formas de comunicação, o ensino de gramática passa a ser visto como um diferencial e deixa de ser uma obrigação sem propósito para se tornar direito do aluno e também objeto de desejo no universo escolar.

Em sala de aula, o professor pode apresentar ao aluno contextos nos quais possa escolher as construções que irá utilizar para compor sua maneira de falar, ampliando todas as competências previstas pela atividade verbal. As aulas de gramática podem, entre suas 
finalidades, chamar a atenção para o funcionamento da língua, destacando sua sistematicidade, e ampliar o conjunto de conhecimentos linguísticos que o usuário possui para o uso efetivo em situações concretas da intenção comunicativa. De acordo com Antunes (2009, p. 68), "efetivamente, seria bem mais produtivo pensar a linguagem; pensar sobre a linguagem; tentar vê-la por dentro; tentar entender o encaixe das peças que fazem seu funcionamento interativo".

Segundo Neves (2002), o lugar ideal para o estudo da gramática é o texto. Entretanto, na rotina escolar, o que se observa é o texto sendo utilizado como mero pretexto para fixação de regras, de nomenclaturas, em atividades puramente metalinguísticas. Na verdade, como ressaltam Possenti (1996) e Neves (2002), atividades envolvendo o estudo do texto deveriam propor ao aluno uma reflexão acerca das relações semânticas e pragmáticas estabelecidas pelo elemento linguístico analisado em determinada situação de uso.

Algumas práticas são próprias da instituição escolar e uma delas consiste no ensino da metalinguagem; no entanto, as atividades no ensino de gramática precisam permitir uma interação na linguagem, uma troca de sentido e intenções. Nessa perspectiva, defendemos um estudo diferenciado das orações subordinadas substantivas, tendo como foco as orações principais e sua importância na formação dos períodos. Propomos uma análise que ultrapasse o nível sintático, tão exaustivamente estudado nas gramáticas tradicionais, ou seja, propomos que o estudo de gramática acompanhe, de fato, o funcionamento pragmático da língua.

Apresentamos a seguir, resumidamente, os princípios gerais do Funcionalismo que estão na base deste artigo; em seguida, discutimos os aspectos das orações subordinadas substantivas a partir dos estudos da Gramática Funcional, destacando a relevância das orações principais nessas construções.

\section{A proposta funcionalista}

O Círculo de Praga, fundado em 1926, trouxe as primeiras manifestações referentes a se pensar na organização das línguas naturais sob o enfoque funcionalista, ou seja, considerando-as a partir das funções comunicativas a que servem. Nessa perspectiva, é o uso que determina a organização linguística, necessitando-se para a análise a consideração acerca dos interlocutores, de suas intenções, do contexto discursivo, ou seja, de toda a situação comunicativa.

De acordo com a perspectiva funcionalista, a língua é vista como instrumento de interação social, e, por essa razão, não há sentido em estudá-la desvinculada de seus usos. Segundo Neves (2001), a gramática funcional busca explicar regularidades dentro das línguas e através delas, em termos de aspectos recorrentes das circunstâncias sob as quais as pessoas usam a língua. Sendo assim, ocupa uma posição intermediária em relação às abordagens que priorizam a sistematicidade da estrutura da língua ou apenas da instrumentalidade de seu uso.

De acordo com Dik (1997), a linguagem não funciona em isolamento: ela é parte integrada de uma realidade humana psicológica e social. Dessa forma, o falante natural de uma língua é um ser humano que executa, no uso comunicativo da linguagem, muitas outras funções além da mera função linguística. Segundo a ideia defendida por Neves 
(2001), esse falante é muito mais do que um "animal linguístico", pois estão envolvidas no uso comunicativo da língua muitas funções humanas, além da linguística.

Analisar um fenômeno linguístico adotando uma abordagem funcionalista é destacar a importância do falante e do ouvinte, o que significa não restringir o fenômeno estudado apenas aos parâmetros da expressão verbal, mas abarcar também as necessidades comunicativas envolvidas (AUGUSTO; BERLINCK; SCHER, 2001). Assim, as expressões linguísticas são examinadas em função do contexto interacional em que são produzidas, o que equivale a dizer, em outras palavras, que nela desempenham um papel fundamental os participantes da interação, o propósito comunicativo e o contexto discursivo.

Na próxima seção, trazemos a descrição dos processos de combinação de orações, priorizando as orações principais das subordinadas substantivas, sob uma perspectiva funcionalista.

\section{Uma visão funcionalista das orações principais em construções com orações subordinadas substantivas}

As propriedades das orações principais em construções completivas normalmente são abordadas superficialmente pela gramática tradicional, não se observando sequer suas funções pragmáticas. No entanto, ao analisarmos as construções completivas a partir de aspectos presentes na oração principal, possibilita-se uma abordagem mais dinâmica e significativa da sintaxe.

Castilho (2012, p. 361) apresenta as propriedades semânticas da oração principal, chamada por ele de sentença matriz. De acordo com o autor, "a sentença matriz expressa uma avaliação do conteúdo proposicional da subordinada substantiva, que é (i) asseverado; (ii) posto em dúvida; (iii) considerado como uma ordem". Para ele, o conteúdo proposicional é enfatizado pelas classes da matriz, revelando um alto grau de adesão do falante em relação à proposição.

Castilho (2012) ressalta ainda a importância do papel das sentenças matrizes na organização do texto, afirmando que, quando olhamos as sentenças matrizes sob esse ângulo, podemos identificar quatro possibilidades (CASTILHO, 2012, p. 364):

Introdução de um tópico discursivo:

(1) Acontece que fulano apareceu quando menos se esperava. E aí...

Declarações sobre esse tópico:

(2) Declarou perante todos que estava exausto.

Argumentação com base em evidências indiretas:

(3) Parece que os deputados estão querendo ver o circo pegar fogo.

Manifestação de nossa vontade sobre qual tópico deveria ser:

(4) Daqui em diante, quero que todo mundo fique lendo dicionários. 
Ao apresentar suas propriedades discursivas, o autor expõe as matrizes de acordo com os verbos que as compõem. Elas são determinadas como: matriz apresentacional (A), matriz declarativa (B), matriz evidencial (C) e matriz volitiva (D). Dessa forma, verificamos que as sentenças matrizes possuem características específicas que devem ser trabalhadas no contexto da sala de aula, inclusive buscando destacar sua importância na construção do discurso. Por exemplo, ao tratar da matriz volitiva, é possível constatar que a presença de verbos volitivos e verbos de suporte retratam a inclinação do falante em relação ao tópico antecipadamente escolhido, podendo também lançar hipóteses que serão possivelmente desenvolvidas na continuação do texto (CASTILHO, 2012, p. 365):

(5) Gostaria de que, pelo menos, três pontos fossem bem examinados pelas autoridades brasileiras. (CASTILHO, 2012, p. 365)

Gonçalves, Casseb-Galvão e Sousa (2008), em seu estudo sobre a subordinação sentencial no português falado culto no Brasil, defendem que os predicados presentes na oração principal de uma subordinada substantiva expressam diferentes valores semânticos com relação ao conteúdo da oração subordinada, podendo ser assim subclassificados em diferentes tipos, a depender do domínio semântico em que se inserem.

Outra análise apresentada pelos autores é a que se refere aos predicados de manipulação. Segundo Gonçalves, Casseb-Galvão e Sousa (2008), essas orações expressam a atitude de um sujeito por meio da qual outro sujeito é compelido, autorizado ou impedido de realizar a ação expressa no complemento sentencial.

Mandaram que todos fossem para a sala de reunião.

Ele era muito organizado, então pedia para que todos nós colocássemos nossas coisas em ordem dentro do armário.

\section{Eu gostaria que você permanecesse aqui por mais algum tempo.}

Podemos perceber nos exemplos acima que há, entre os predicados, uma diferença no que se refere à intensidade da manipulação expressa. $\mathrm{O}$ predicado mandar, apresenta uma manipulação mais intensa do que o predicado pedir, e a forma gostaria que indica manipulação ainda menos intensa em relação aos outros dois predicados. Gonçalves, Casseb-Galvão e Sousa (2008, p. 1020) destacam que "esse último caso corresponde a uma forma cristalizada na língua, que funciona como uma estratégia de polidez de que o falante se vale para atenuar a imposição de seu ato manipulativo sobre um interlocutor". Os autores afirmam que, no corpus por eles analisado, os verbos que aparecem como predicados de manipulação são: mandar, fazer (com que), pedir, gostar (-ia que), impedir, proibir, exigir e querer.

A análise de orações complexas em que o predicado é o verbo "ser" mais um adjetivo nos permite observar que a natureza predicativa da oração principal, através da escolha do adjetivo, já representa, de certa forma, a subjetividade do falante.

Estamos considerando que, em sala de aula, tal constatação pode trazer mais significado para o estudo da sintaxe, uma vez que o aluno poderá analisar tais aspectos da oração principal presentes em diversos gêneros textuais e na construção de seu próprio discurso. Por exemplo, podem-se usar construções demonstrando situações em que o falante se comprometa mais ou menos em suas afirmações. As subordinadas substantivas 
subjetivas formadas pela expressão "ser + adjetivo" permitem que o falante apresente a maneira como avalia a realidade, a partir de suas concepções, valores e crenças. Entretanto, ao contrário do que acontece com as construções constituídas por verbos de atividade mental, elas se mostram menos comprometedoras, visto que o falante tem sua face "apagada" (SPERANÇA-CRISCUOLO, 2011, p. 121). Dessa forma, cabe ao falante, dependendo das intenções e do contexto, escolher qual é a construção a ser utilizada. Além disso, no âmbito escolar, o professor pode ajudar o aluno a perceber o modo como ele próprio utiliza a língua, possibilitando uma reflexão sobre seus usos.

As orações que apresentam verbos dicendi como predicador da oração principal, por sua vez, permitem que as construções sintáticas com oração subordinada substantiva objetiva direta assumam a função de inserir outras vozes ao discurso do falante, devido à própria natureza do predicador: um verbo de elocução (mesmo que outros verbos possam assumir essa função). Segundo Sperança-Criscuolo (2011), ocorre a possibilidade da inserção de outras vozes ao discurso de um Enunciador, tais como a integração da voz do outro e a integração da própria voz.

Em relação à integração da voz do outro, podemos constatar a sua presença em textos argumentativos, por exemplo. Em artigos de opinião, textos de divulgação científica e de revistas acadêmicas, a inserção da voz do outro representa, de uma perspectiva mais geral, o apoio à argumentação que se desenvolve. Essa constatação é bastante interessante para o trabalho em sala de aula, em especial para as atividades do $9^{\circ}$ ano do ensino fundamental, visto que o artigo de opinião é um gênero textual bastante estudado nessa série. A análise da OP e sua construção com verbos dicendi podem ser atividades trabalhadas com os alunos, levando-os a perceber que, no artigo de opinião, é bastante comum a integração da voz do outro, buscando a construção da crítica pretendida pelo autor.

Atividades que envolvam o estudo de gramática, em sala de aula, precisam ser reflexivas, levando à produção de sentidos ou efeitos e, consequentemente, conforme afirma Neves (2012, p. 209), resultam "em uma apropriação de gatilhos que disparem usos apropriados e significativos em cada diferente situação". A partir de uma perspectiva funcionalista, a abordagem de um tópico gramatical pode contribuir de forma efetiva para o desenvolvimento das habilidades comunicativas do aluno, quer seja em relação à produção, quer seja em relação à compreensão de textos.

\section{As orações subordinadas em livros didáticos: uma análise comparativa}

Em nossa análise, verificamos que os autores de LD, com o passar dos anos, têm procurado incorporar novas orientações para as atividades de análise linguística, apresentando tentativas de inovação para o ensino de gramática. Consideramos, inclusive, positivo e "inovador" (levando-se em consideração a resistência que encontramos para a inovação nas aulas de gramática) a introdução do conceito de "prática de análise linguística" na produção desse material didático.

Os livros escolhidos para formar nosso corpus dividem-se entre antes e depois dos Parâmetros Curriculares Nacionais (PCN) (BRASIL, 1997), visto que alguns foram publicados antes de 1998 e outros datam de 2012. Ressaltamos que, nos livros analisados, nos limitamos a observar apenas as seções destinadas aos exercícios gramaticais correspondentes ao estudo das orações subordinadas substantivas. A escolha de vários 
exemplares - no total, sete - deve-se ao fato de que nossa análise está voltada apenas para o estudo das orações subordinadas (substantivas), com foco na oração principal. No Quadro 1, estão as informações sobre os livros utilizados:

Quadro 1. Referências dos livros didáticos analisados

\begin{tabular}{|l|l|l|l|}
\hline \multicolumn{1}{|c|}{ Livro } & \multicolumn{1}{|c|}{ Autor } & \multicolumn{1}{c|}{ Editora } & Ano \\
\hline Texto e Contexto (LD 1) & Lídio Tesoto & $\begin{array}{l}\text { Editora do Brasil } \\
\text { S/A }\end{array}$ & 1986 \\
\hline Palavra e Criação (LD 2) & Dirce Guedes de Azevedo & FTD & 1997 \\
\hline $\begin{array}{l}\text { Português Linguagens \& } \\
\text { Realidade (LD3) }\end{array}$ & $\begin{array}{l}\text { Roberto Melo Mesquita e Cloder } \\
\text { Rivas Martos Saraiva }\end{array}$ & 1997 \\
\hline $\begin{array}{l}\text { Vontade de Saber Português } \\
\text { LD4) }\end{array}$ & $\begin{array}{l}\text { Rosemeire A. Tavares e Tatiane } \\
\text { B.Conselvan }\end{array}$ & FTD & 2012 \\
\hline $\begin{array}{l}\text { Singular \& Plural (LD5) } \\
\text { Laura de Figueiredo, Marisa Balthasar } \\
\text { e Shirley Goulart }\end{array}$ & $\begin{array}{l}\text { Moderna } \\
\text { Carvalho Delamanto e Laiz B. de }\end{array}$ & Saraiva & 2012 \\
\hline Jornadas. Port (LD6) & $\begin{array}{l}\text { William Roberto Cereja e Thereza } \\
\text { Cochar Magalhães }\end{array}$ & Saraiva & 2012 \\
\hline Português Linguagens (LD7)
\end{tabular}

Em virtude do recorte que fizemos, apresentaremos a seguir apenas alguns exemplos de atividades analisadas.

A Figura 1, do livro Texto e Contexto (1986), apresenta uma atividade cujo único fim é nomear as orações subordinadas substantivas, ou seja, trata-se de uma atividade meramente classificatória, desprovida de significado.

(2) Grife a subordinada substantiva e diga se ela é subjetiva ou objetiva direta:

a) E possível que o réu seja absolvido.

b) O ministro esclareceu que o projeto era irrealizável.

c) Os bóias-frias afirmaram que suas condições de trabalho eram desumanas.

objotive direts

d) E necessário que todos respeitem a sinalização. subjerive

e) Receava que o filho não entendesse sua exigência. objotive dira

f) E conveniente que você afixe as instruções no mural.

Figura 1. Exemplos de atividade - Livro Texto e Contexto, p. 89 - Lídio Tesoto - Editora do Brasil S/A - 1986

Não há, na atividade apresentada, nenhum direcionamento para se explorar semântica e discursivamente os períodos apresentados. No entanto, conforme nossa perspectiva de abordagem, o professor poderia, neste exercício, apresentar as diferenças 
entre a construção de uma objetiva direta e uma subjetiva, destacando o apagamento ou a presença do sujeito nessas orações. Na subjetiva $\dot{E}$ conveniente que você afixe as informações no mural, tem-se um sujeito apagado, diferente da construção $O$ ministro esclareceu que o projeto era irrealizável, em que o enunciador está claramente expresso. Além disso, é possível observar que, nas construções formadas por ser + adjetivo, como na frase É necessário que todos respeitem a sinalização, a natureza predicativa da oração principal, através da escolha do adjetivo, já representa, de certa forma, a subjetividade do falante.

Nas Figuras 2 e 3, temos novamente atividades que pedem apenas a classificação e identificação das orações subordinadas, sem levar o aluno a refletir sobre os efeitos de sentido do uso dessas construções.

1. Diga se a oração em destaque é subordinada adverbial, adjetiva ou substantiva:

a. Já que você não está bem, não vá à escola hoje.

adverbial

b. Comprei os livros que você me indicou. adjetiva

c. Convém que você descanse mais. substantiva

Figura 2. Exemplo de atividade - Livro: Português Linguagens \& Realidade, p. 77 Roberto Melo Mesquita e Cloder Rivas Martos - Saraiva - 1997

2. Classifique a oração subordinada substantiva ern destaque:

a. O professor afirma que esta classe é muito boa. objetiva direta

b. A verdade é que eles foram ao cinema. predicativa

c. Ê bom que você volte logo. subjetiva

d. Lembre-se de que faltam dois dias para a prova.

objetiva indireta

e. Tive a sensação de que a britadeira me furava os tímpanos. compl. nominal

f. Ele me disse apenas isto: a nossa sociedade acabou.

apositiva

Figura 3. Exemplo de atividade - Livro: Português Linguagens \& Realidade, p. 77 Roberto Melo Mesquita e Cloder Rivas Martos - Saraiva - 1997 
De certa forma, em todas as atividades analisadas em livros anteriores aos PCN, constatamos a maneira equivocada de se trabalhar o estudo das orações subordinadas em sala de aula. São frases soltas, construídas para fazer parte dos exercícios, desligadas de qualquer situação real de uso e de funcionalidade. Além disso, não há exploração dos processos sintáticos que diferenciam essas orações. Podemos perceber que essa forma de abordagem faz com que o aluno conceba a língua como homogênea, fixa, ordenada, independente de seu contexto de produção, quando, na verdade, a língua não é exata, é heterogênea e a reflexão sobre seu uso acrescenta ao falante os mecanismos para utilizála de forma eficiente. São exercícios que silenciam a funcionalidade da língua, centrando o ensino da sintaxe principalmente na nomenclatura, levando-se em conta somente a observação de como se organizam os elementos linguísticos para formar frases e sua classificação.

\section{O ensino gramatical em livros didáticos mais atuais}

Conforme já expusemos aqui, ainda encontramos aulas de gramática baseadas apenas no que é proposto pelos manuais tradicionais, em que a língua é concebida como um sistema estático e estável. Dessa forma, buscamos encontrar no material didático analisado (posterior ao PCN) atividades que se aproximassem da concepção do ensino de gramática como um todo, considerando-se todos os elementos envolvidos no funcionamento da língua e no seu uso. No entanto, não podemos afirmar que encontramos exercícios que satisfaçam completamente nossas expectativas em relação ao trabalho com as orações subordinadas substantivas, mas pudemos constatar uma significativa melhora nessa abordagem. Cabe ressaltar que o olhar atento do professor, ao fazer a escolha do LD para utilizar em sua sala de aula, é de suma importância, pois podemos encontrar, atualmente, livros cujos autores continuam presos aos manuais da gramática normativa. Como alternativa para o bom aproveitamento desse material didático, propomos que o professor faça uso da diversidade de gêneros textuais presentes nos LD para desenvolver estudos gramaticais sob uma perspectiva funcionalista.

Na Figura 4, a seguir, observamos uma preocupação em relacionar a atividade a um texto, buscando uma abordagem semântica e discursiva das orações. Neste exercício, para responder à pergunta (d), por exemplo, o aluno pode ser levado a fazer uma análise linguístico-discursiva também da oração principal, no sentido de relacionar a repetição estrutural dessa oração à ênfase à subjetividade do eu-lírico. Nesse caso, não se trata de se analisar somente a função sintática que a subordinada exerce em relação à oração principal, nem tampouco ficar preso a uma análise meramente classificatória.

As orações principais em orações completivas (subordinadas substantivas) podem apresentar modalizadores pragmáticos subjetivos, os quais põem em relevo os sentimentos despertados no locutor pelo conteúdo sentencial (CASTILHO, 2012, p. 363). A atividade, que apresenta uma abordagem semântico discursiva, pode ampliar a compreensão do exercício em relação à função das orações subordinadas, caso o professor apresente também a análise da oração principal. Essa análise possibilitaria o estudo da natureza predicativa da oração principal que pressupõe, já pela escolha do adjetivo, a subjetividade do falante que avalia o conteúdo expresso na oração subordinada (SPERANÇA-CRISCUOLO, 2011). 
6. Leia este poema.

\section{Dialética}

É claro que a vida é boa

E a alegria, a única indizível emoção

É claro que te acho linda

Em ti bendigo o amor das coisas simples

É claro que te amo

E tenho tudo para ser feliz

Mas acontece que eu sou triste...

Vinícius de Moraes. Poesia completa e prosa. Rio de Janeiro: José Aguilar, 1974

a) O eu poético trabalha com uma oposição de significados. Qual é ela? Explique. Ele tem tudo para ser feliz, mas é triste.

b) Releia estes versos.

"É claro que a vida é boa"

"É claro que te acho linda"

"É claro que te amo"

Que tipo de oração subordinada é usada para explicar os motivos do eu poético para ser feliz?

c) A oração "[...] que sou triste..." é também uma subordinada. Ela se classifica da mesma forma que as anteriores? Sim, também é uma substantiva subjetiva.

d) O uso predominante desse tipo de oração no poema contribui para enfatizar o que acontece cor o eu poético? Explique. Possibilidade: Sim; nesses versos, ao usar repetidamente nas oraçōes principais

1.

a expressăo é claro, o eu poético deixa evidente que conhece seus sentimentos.

Figura 4. Exemplos de atividade - livro: Jornadas. Port, p. 110 - Dileta Delamanto e Laiz

B. de Carvalho - Saraiva - 2012

\section{O enfoque funcionalista das orações principais: outras possibilidades de abordagem para o livro didático}

Os estudos apresentados pela Linguística e a publicação dos PCN têm levado alguns autores de LD a buscar uma nova forma de se trabalhar as atividades gramaticais nos materiais didáticos. Essa mudança tem sido lenta, entretanto, como mostramos em alguns exemplares de LD que estão no corpus de nossa pesquisa, já podemos encontrar mudanças na abordagem de atividades relativas ao estudo da sintaxe.

Nossa proposta de análise tem como finalidade contribuir para que o LD seja utilizado de maneira produtiva no contexto escolar, e o estudo das subordinadas substantivas também receba uma abordagem diferente nas aulas de gramática. Entendemos que apresentar um enfoque diferente em relação à oração principal, mostrando que as orações subordinadas substantivas recebem seu enquadramento semântico do predicado matriz em que se encaixam, ou seja, da construção da oração principal, resultará em atividades mais significativas na sala de aula.

Retomemos o poema de Vinícius de Moraes (Figura 4):

Dialética

É claro que a vida é boa

E a alegria, a única indizível emoção

É claro que te acho linda

Em ti bendigo o amor das coisas simples

É claro que te amo 
E tenho tudo para ser feliz

Mas acontece que eu sou triste...

Além das atividades apresentadas no LD para se trabalhar com o poema, podemos destacar as características das subordinadas subjetivas constantes no texto. Na expressão É claro temos a presença de um predicado modal epistêmico que relaciona o grau de certeza do falante com o conteúdo da oração subordinada, ressaltando sua subjetividade e seu comprometimento com o que é dito. No final do texto, o uso do verbo Acontecer no verso Mas acontece que eu sou triste apresenta a introdução de um tópico discursivo, mudando o direcionamento da reflexão do poema.

Embora essas relações possam ser explicadas mesmo no ensino fundamental, não é viável que o professor cobre essa nova nomenclatura ou peça aos alunos que classifiquem essas relações. Afinal, essa prática recairia em uma abordagem tradicional; a intenção é levar os alunos a refletir sobre essas construções, a partir da perspectiva apresentada. Recorrer aos textos presentes nos LDs, mesmo fora das seções destinadas ao estudo gramatical, é uma possibilidade de diversificação das aulas de estudo da língua.

$\mathrm{Na}$ Figura 5, destacamos o quinto parágrafo do texto Nova data para celebrar o Dia da Língua Portuguesa: 5 de maio para análise. A frase de Marcos Bagno, "É preciso estar sempre alerta para não acontecer o controle social por meio da linguagem.", possibilita o estudo da construção "ser + adjetivo" e a análise da oração reduzida. Observamos que, ao escolher o termo preciso, Bagno está sendo enfático em seu posicionamento, entretanto, não assume uma postura autoritária. Além disso, o uso da oração reduzida, sem a marcação de sujeito, dá ênfase ao fato de "estar sempre alerta", o que é sugerido a todas as pessoas e não somente ao linguista.

\section{Defensor das mais diversas formas como} o português é falado, o linguista Marcos Bagno, professor da Universidade de Brasília, condena o uso da língua como forma de domínio entre classes sociais. "É preciso estar sempre alerta para não acontecer o controle social por meio da linguagem. As relações sociais devem ser democráticas e igualitárias", defende.

Figura 5. Exemplos de atividade - Livro: Vontade de saber português, p. 51 - FTD-2012 Rosemeire A. Tavares e Tatiane B. Conselvan

Consideramos que, ao levar para a sala de aula essa abordagem da gramática que está muito além de saber descrever e classificar orações -, podemos ampliar a compreensão dos alunos a respeito da construção da sua própria língua, mostrando que estudar gramática, especificamente, sintaxe, é refletir sobre as inúmeras possibilidades que a língua nos oferece de nos comunicarmos de maneira eficiente nas mais diversas situações de uso. 


\section{Conclusão}

Nossa principal motivação para desenvolver um trabalho que envolvesse o ensino de gramática foi a desassociação presente nas salas de aula entre o baixo desempenho linguístico dos alunos na compreensão e produção de textos e o estudo de gramática, como se esse estudo não estivesse diretamente ligado ao aprendizado de usos eficientes da língua nos mais diferentes contextos de comunicação.

Corroboramos a ideia defendida por Sperança-Criscuolo (2011) de que o estudo do processo de subordinação, com ênfase nas orações principais, pode trazer contribuições para o ensino/aprendizagem da sintaxe, municiando professores e alunos para o desenvolvimento mais eficiente de leitura e produção de textos nas mais diversificadas modalidades comunicativas.

A opção por constituir nosso corpus com livros didáticos deve-se ao fato de que esse material é um dos instrumentos mais presentes nas salas de aula das escolas públicas e, de certa forma, um dos poucos recursos dos quais o professor dispõe para sua atuação. De acordo com Lajolo (1996), é um instrumento de grande importância para o contexto de aprendizagem formal, podendo ser decisivo para a qualidade do aprendizado resultante das atividades no âmbito escolar. Optamos por selecionar livros mais antigos (anteriores aos PCN) e outros mais atuais (posteriores aos PCN), buscando demostrar que, apesar dos problemas, é possível constatar uma evolução na abordagem destinada ao ensino das construções complexas. Com o passar dos anos, os autores de LD têm procurado incorporar novas orientações para as atividades de análise linguística, apresentando tentativas de inovação para o ensino de gramática.

A contribuição deste trabalho está na proposição de uma abordagem mais significativa dos estudos de sintaxe presentes no LD, em especial na análise das orações completivas, oferecendo subsídios para um tratamento destinado à gramática sob um enfoque funcionalista de análise da língua.

\section{REFERENCIAS}

ANTUNES, I. Muito Além da Gramática. São Paulo: Parábola Editorial, 2009.

AUGUSTO, M. R. A.; BERLINCK, R. A.; SCHER, A. P. Sintaxe. In: MUSSALIN, F.; BENTES, A. C. (Org.). Introdução à linguística: domínios e Fronteiras. v. I São Paulo: Cortez, 2001.

BRASIL. PCN - Parâmetros Curriculares Nacionais. Ensino Fundamental: Língua Portuguesa. Brasília. MEC/SEF, 1997.

CASTILHO, A. T. Nova gramática do português brasileiro. São Paulo: Editora Contexto, 2012.

CEREJA, W. R.; MAGALHÃES, T. C. Português: Linguagens. 7. ed. São Paulo: Saraiva, 2012.

DELMANTO, D.; CARVALHO, L. B. Jornadas. Port. 2. ed. São Paulo: Saraiva, 2012.

DIK, C. S. The Theory of Functional Grammar. In: HENGEVELD, K. (Ed.). Complex and Derived Constructions. Part 2. Berlin; New York: Mouton de Gruyter, 1997. 
GONÇALVES, S. C. L.; CASSEB-GALVÃO, V. C.; SOUSA, G. C. As construções subordinadas substantivas. In: NEVES, M. H. M.; CASTILHO, A. T. (Org.). Gramática do português falado culto no Brasil: classe de palavras e processos de construção. Campinas: Editora da UNICAMP, 2008.

LAJOLO, M. Livro Didático: um quase manual de usuário. In: Em aberto. Livro Didático e qualidade de ensino. Ano 16, n. 69. Brasília: jan./mar, 1996.

MARTOS, C. R.; MESQUITA, R. M. Português Linguagem \& Realidade. 9. ed. São Paulo: Saraiva, 1997.

NEVES, M. H. M. A gramática funcional. São Paulo: Martins Fontes, 2001. A gramática: história, teoria e análise, ensino. São Paulo: Editora UNESP, 2002. - A gramática passada a limpo: conceitos, análises e parâmetros. São Paulo: Parábola Editorial, 2012.

POSSENTI, S. Por que (não) ensinar gramática na escola. Campinas: Mercado das Letras, 1996.

SILVA, A. A. As orações principais em construções completivas do português: uma contribuição para o ensino. 2015. 120 f. Dissertação (Mestrado PROFLETRAS) Faculdade de Ciências e Letras, Universidade Estadual Paulista, Assis/Araraquara.

SPERANÇA-CRISCUOLO, A. C. Orações subordinadas substantivas sob uma perspectiva funcionalista-cognitivista: uma proposta de descrição e ensino. $2011.156 \mathrm{f}$. Tese (Doutorado em Linguística e Língua Portuguesa) - Faculdade de Ciências e Letras, Universidade Estadual Paulista, Araraquara.

TAVARES, R. A. A.; CONSElVAN, T. B. Vontade de saber português. São Paulo, 2012.

TESOTO, L. Texto e Contexto. São Paulo, 1986.

Recebido em: 14/08/2016

Aprovado em: 05/03/2017 